\title{
STUDY OF ACUTE PHASE RESPONSE IN PATIENTS WITH CHRONIC RENAL FAILURE ON HAEMODIALYSIS
}

\author{
Sudha Ayyagari ${ }^{1}$, Bheeshma Byram ${ }^{2}$
}

${ }^{1}$ Assistant Professor, Department of Pathology, Kamineni Academy of Medical Sciences and Research Centre, L.B. Nagar, Hyderabad. ${ }^{2}$ Associate Professor, Department of Pathology, Gandhi Medical College, Hyderabad.

\begin{abstract}
In recent times, significant attention has been paid to the study of acute phase reactants in patients with Chronic Renal Failure (CRF) undergoing haemodialysis. Alpha-1 antitrypsin is a proteinase inhibitor and represents a defense mechanism to protect the tissues from proteolytic enzyme activity. In CRF, the leucocyte function appears to be impaired because of coexisting acidosis, hyperglycaemia, and azotaemia. However, dialysis membranes can induce neutrophil activation, which can be studied by the nitroblue tetrazolium test.
\end{abstract}

\section{AIMS AND OBJECTIVES}

To study the serum alpha- 1 antitrypsin levels in patients of CRF on long-term dialysis at different intervals (before, immediately after, and 8 hours after dialysis) and to appreciate and establish the extent of neutrophil activation in CRF patients by the nitroblue tetrazolium test.

\section{MATERIALS AND METHOD}

The present study was a prospective one carried out in the Departments of Pathology and Nephrology at Osmania Medical College and Osmania General Hospital over a period of two and a half years. A total of 50 patients with chronic renal failure who were on regular haemodialysis were selected for the study. Serum alpha-1 antitrypsin levels were studied in three samples, predialysis, immediately after dialysis, and 8 hours after dialysis by using a spectrophotometer. The nitroblue tetrazolium test was done in 25 patients in fresh EDTA anticoagulated blood smears stained by nitroblue tetrazolium and neutrophils containing black formazan pigment were considered to be NBT positive.

\section{RESULTS}

The serum levels of alpha-1 AT of CRF patients was taken as a whole and compared to that of control. The results were also compared according to the time bound frequency and some trends were observed, which were grouped into four types.

Group A-This group exhibited almost a normal level of serum levels of alpha-1 AT throughout (before, immediately after, and 8 hours after dialysis). Group B-This group showed an initial normal level to an abnormal final level. Group C-This group showed an initial abnormal level and a normal postdialysis level. Group D-This group maintained an abnormal level throughout. For the NBT reduction test, an increase after dialysis was noted in all the four groups with a significant increase in B and D groups.

\section{CONCLUSIONS}

A general phenomenon of acute phase response with raised serum alpha-1 AT and raised NBT positivity is seen in CRF patients. Underlying diseases along with their biochemical and metabolic abnormalities have a role in acute phase reaction. Dialysis procedure also seems to have a role in inducing persistent acute phase reaction in a small population of CRF patients and one has to be watchful for sequelae of adverse reactions thereof in such patients.

\section{KEYWORDS}

Serum Alpha-1 Antitrypsin, Haemodialysis, Nitroblue Tetrazolium Test, Acute Phase Reactants, Chronic Renal Failure.

HOW TO CITE THIS ARTICLE: Ayyagari S, Byram B. Study of acute phase response in patients with chronic renal failure on haemodialysis. J. Evolution Med. Dent. Sci. 2016;5(69):4980-4983, DOI: 10.14260/jemds/2016/1131

\section{INTRODUCTION}

In recent times, significant attention has been paid to the study of acute phase reactants in patients with Chronic Renal Failure (CRF) undergoing haemodialysis. Alpha-1 antitrypsin (alpha$1 \mathrm{AT}$ ) is a proteinase inhibitor and represents a defense mechanism to protect the tissues from proteolytic enzyme activity. Other acute phase reactants are C-reactive protein,

Financial or Other, Competing Interest: None.

Submission 20-07-2016, Peer Review 13-08-2016,

Acceptance 19-08-2016, Published 27-08-2016.

Corresponding Author:

Dr. Sudha Ayyagari,

\#16-11-16/M/38,

East Prashant Nagar, Moosarambagh,

Malakpet, Hyderabad-500036.

E-mail: ayyagarisudha@yahoo.com

DOI: $10.14260 /$ jemds/2016/1131 haptoglobin, and orosomucoid in the serum of acutely ill patients. In CRF, the leucocyte function appears to be impaired because of coexisting acidosis, hyperglycaemia, and azotaemia.[1] However, dialysis membrane itself can induce neutrophil activation.

\section{AIMS AND OBJECTIVES}

To study the serum alpha-1 antitrypsin levels in patients of CRF on long-term dialysis at different intervals (before, immediately after, and 8 hours after dialysis) and to appreciate and establish the extent of neutrophil activation in CRF patients by the Nitroblue Tetrazolium Test (NBT test).

\section{MATERIALS AND METHODS}

The present study was a prospective one carried out in the Departments of Pathology and Nephrology at Osmania Medical 
College and Osmania General Hospital over a period of two and a half years.

A total of 50 patients with chronic renal failure who were on regular haemodialysis with cellulose acetate membrane were selected for the study. Thirty healthy subjects in age range of 12-50 years were similarly selected to serve as normal controls in this study and they were devoid of any condition that would have altered the acute phase reactants.

$2 \mathrm{~mL}$ of clotted blood and $1 \mathrm{~mL}$ of fresh EDTA anticoagulated blood were collected for serum alpha-1 AT assay and nitroblue tetrazolium test respectively. Serum alpha-1 AT assay was performed on each patient at three different intervals, viz., before, immediately after, and eight hours after dialysis, and the Albert et al[2] protocol was followed. Serum from each sample was separated within one hour and stored at 25 degrees $C$ until analysis. Analysis was done either immediately or before 48 hours after collection. Blood samples for NBT were drawn at two different intervals before and after dialysis. The test was done within one hour after collection.

The principle of serum alpha-1 AT assay is that the antitryptic proteins of serum inhibit the hydrolysis of alpha-Nbenzoyl-DL-arginine-P-nitroanilide (BAPNA) by trypsin in Tris buffer. The reaction is stopped by adding acetic acid and the absorbance is then read at $400 \mathrm{~nm}$. At this wavelength, the liberated P-nitroaniline (PNA) has a molar absorptivity of 10,500 . Protein must be present in the assay control if concentration and absorbance are to be linearly related. The test was done using the spectrophotometer.

The principle of NBT test is detection of increased enzymatic activity of neutrophils, which is capable of reducing nitroblue tetrazolium to formazan, which forms a black precipitate. In this procedure, blood was mixed with nitroblue tetrazolium, allowed to incubate, smears were made, and counterstained with Leishman's stain and examined for the neutrophils containing formazan. In healthy adults, $10 \%$ or less of the neutrophils contain formazan. In the presence of bacterial infection, up to $70 \%$ of neutrophils can be positive. ${ }^{[3]}$

\section{RESULTS}

The serum levels of alpha-1 AT of CRF patients was taken as a whole and compared to that of control. The results were also compared according to the time bound frequency and some trends were observed, which were grouped into four types.

Group A This group exhibited almost a normal level of serum levels of alpha-1 AT throughout (before, immediately after, and 8 hours after dialysis). Presenting symptoms were of uraemia and some patients had past history of renal disease. None of the patients had diabetes mellitus or hypertension. (Table 1).

Group B This group showed an initial normal level to an abnormal final level. The presenting symptoms were of uraemia and some patients had past history of renal disease. Half of the patients had diabetes mellitus and all were hypertensive. (Table 2).

Group C This group showed an initial abnormal level and a normal postdialysis level. None of the patients had diabetes mellitus. Hypertension was detected in 6 out of 13 patients. (Table 3).
Group D This group maintained an abnormal level throughout. 3 out of 18 patients were diabetic and 11 were hypertensive. (Table 4).

NBT reduction test was done on 25 patients and the results were analysed group wise. In 3 patients, the percentage of NBT positive cells could not be counted due to technical reasons. The increase after dialysis was noted in all the four groups with a significant increase in B and D groups. (Table 5).

\begin{tabular}{|c|c|c|c|}
\hline No. & $\begin{array}{c}\text { Before } \\
\text { Dialysis }\end{array}$ & $\begin{array}{c}\text { Immediately } \\
\text { After }\end{array}$ & $\begin{array}{c}\text { 8 hrs. After } \\
\text { Dialysis }\end{array}$ \\
\hline 1 & 3.85 & 3.89 & 3.98 \\
\hline 2 & 3.8 & 2.64 & 4.03 \\
\hline 3 & 4 & 4 & 4.03 \\
\hline 4 & 3.69 & 3.12 & 3.09 \\
\hline 5 & 2.51 & 2.26 & 2.15 \\
\hline 6 & 3.98 & 4 & 4 \\
\hline 7 & 2.13 & 2.13 & 2.69 \\
\hline 8 & 2.52 & 2.27 & 2.16 \\
\hline 9 & 2.6 & 4.69 & 3.93 \\
\hline \multicolumn{4}{|c|}{ Table 1: Serum Alpha-1 AT Levels in Group A } \\
\hline
\end{tabular}

\begin{tabular}{|c|c|c|c|}
\hline No. & $\begin{array}{c}\text { Before } \\
\text { Dialysis }\end{array}$ & $\begin{array}{c}\text { Immediately } \\
\text { After }\end{array}$ & $\begin{array}{c}\text { 8 hrs. After } \\
\text { Dialysis }\end{array}$ \\
\hline 1 & 3.46 & 3.58 & 4.21 \\
\hline 2 & 3.45 & 3.52 & 4.2 \\
\hline 3 & 3.6 & 3.72 & 4.11 \\
\hline 4 & 3.4 & 3.52 & 3.8 \\
\hline 5 & 4.05 & 4.08 & 5.01 \\
\hline 6 & 2.74 & 3.82 & 4.92 \\
\hline 7 & 3.88 & 4.39 & 5.02 \\
\hline 8 & 3.92 & 4.72 & 4.62 \\
\hline 9 & 3.08 & 5.07 & 4.5 \\
\hline 10 & 3.95 & 4.19 & 4.24 \\
\hline \multicolumn{4}{|c|}{ Table 2: Serum Alpha-1 AT Levels in Group B } \\
\hline
\end{tabular}

\begin{tabular}{|c|c|c|c|}
\hline No. & $\begin{array}{c}\text { Before } \\
\text { Dialysis }\end{array}$ & $\begin{array}{c}\text { Immediately } \\
\text { After }\end{array}$ & $\begin{array}{c}\text { 8 hrs. After } \\
\text { Dialysis }\end{array}$ \\
\hline 1 & 5.16 & 5.2 & 4 \\
\hline 2 & 4.39 & 4 & 4.07 \\
\hline 3 & 4.41 & 4 & 3.41 \\
\hline 4 & 4.55 & 4.05 & 3.32 \\
\hline 5 & 5.09 & 4.65 & 3.47 \\
\hline 6 & 4.66 & 4.48 & 4.06 \\
\hline 7 & 4.59 & 4.29 & 3.59 \\
\hline 8 & 5.6 & 5.22 & 4.7 \\
\hline 9 & 6.38 & 4.78 & 2.75 \\
\hline 10 & 6.12 & 4.59 & 2.89 \\
\hline 11 & 4.2 & 3.6 & 3.31 \\
\hline 12 & 4.35 & 4.39 & 3.65 \\
\hline 13 & 4.88 & 5.03 & 3.77 \\
\hline \multicolumn{3}{|c|}{ Table 3: Serum Alpha-1 AT Levels in Group C } \\
\hline
\end{tabular}

\begin{tabular}{|c|c|c|c|}
\hline No. & $\begin{array}{c}\text { Before } \\
\text { Dialysis }\end{array}$ & $\begin{array}{c}\text { Immediately } \\
\text { After }\end{array}$ & $\begin{array}{c}\text { 8 hrs. After } \\
\text { Dialysis }\end{array}$ \\
\hline 1 & 4.19 & 4.88 & 5.19 \\
\hline 2 & 4.96 & 5.42 & 4.22 \\
\hline 3 & 4.22 & 4.42 & 4.42 \\
\hline 4 & 5.09 & 3.85 & 4.62 \\
\hline
\end{tabular}




\begin{tabular}{|c|c|c|c|}
\hline 5 & 4.63 & 4.64 & 4.49 \\
\hline 6 & 4.92 & 5.02 & 4.92 \\
\hline 7 & 7.32 & 6.96 & 7.7 \\
\hline 8 & 5.11 & 5.11 & 5.65 \\
\hline 9 & 5.8 & 4.7 & 5.2 \\
\hline 10 & 5.52 & 5.42 & 5.43 \\
\hline 11 & 4.59 & 4.79 & 4.79 \\
\hline 12 & 4.61 & 4.66 & 4.66 \\
\hline 13 & 4.41 & 4.41 & 4.61 \\
\hline 14 & 4.34 & 4.22 & 4.15 \\
\hline 15 & 4.55 & 4.55 & 4.55 \\
\hline 16 & 4.92 & 4.96 & 5.05 \\
\hline 17 & 4.78 & 5.04 & 5 \\
\hline 18 & 5.22 & 4.42 & 4.42 \\
\hline \multicolumn{3}{|c|}{ Table 4: Serum Alpha-1 AT Levels in Group D } \\
\hline
\end{tabular}

\begin{tabular}{|c|c|c|}
\hline Group & Before Dialysis & After Dialysis \\
\hline A & $56.3 \%$ & $62.0 \%$ \\
\hline B & $16.0 \%$ & $47.5 \%$ \\
\hline C & $46.5 \%$ & $51.6 \%$ \\
\hline D & $18.0 \%$ & $43.0 \%$ \\
\hline \multicolumn{2}{|c|}{ Table 5: NBT Positivity Before and After Dialysis in the } \\
Four Groups (Averages) \\
\hline
\end{tabular}

\section{DISCUSSION}

A total of 50 patients were studied and serum alpha- 1 AT was estimated at three time-bound intervals along with the alpha$1 \mathrm{AT}$ in 30 normal control subjects. The NBT test was done on 25 patients in both pre- and postdialysis samples.

The serum alpha-1 AT in patients with CRF revealed an overall increase irrespective of the time of sampling in the dialysis setting. The results of the NBT tests also showed an overall increase in the NBT positivity, irrespective of the time of sampling, pre- or postdialysis. These observations reflect the generally pervading acute phase response in these patients, which is envisaged to be due to the underlying disease process with its varied pathophysiologic, biochemical, and metabolic aberrations. Factors involved in the dialysis procedure and the dialysing membrane itself may also contribute.

A closer look at the levels of serum alpha-1 AT revealed some definite groups based on the levels before dialysis, immediately after, and 8 hours after dialysis. These groups are called A, B, C, and D as mentioned earlier. 18\% patients fell in A group who exhibited normal serum alpha-1 AT levels in all three samples. No effect of either disease or dialysis was seen in these patients. Similar results have been reported by Docci et al[4] who reported lower mean serum alpha-1 AT in 23 uncomplicated haemodialysis patients. Group B had 20\% patients in whom a normal predialysis level culminated into an elevated abnormal level. This rising group in the acute phase reaction could be due to the dialysis procedure alone. The disease process could not have resulted in this sequential increase. Horl et al[5] found significant increased alpha-1 AT activity during haemodialysis using polyacrylonitrile or polysulfone membranes. They also found that the level of plasma alpha-1 AT in complex with elastase increased significantly during dialysis and concluded that neutral granulocyte proteinases can be released during haemodialysis independent of the change of leucocyte count during the first

hour of dialysis therapy. Koudsen et al[6] found that enzyme alpha 1 PI (proteinase inhibitor) complex rose progressively during dialysis and disappeared at half-life of 2.5 hours. Group C had $26 \%$ patients in whom an initial high level of serum alpha-1 AT returned to normal at the end of the study. In these patients, dialysis appears to help to decrease the acute phase response, which was brought about by the disease process itself in which biochemical and metabolic factors are responsible. Trznadel et al[7] found slight changes in the level of alpha-1 AT during dialysis, but significant decreases were found seven hours after termination of dialysis with cuprophane membrane. Shcherbakova et al[8] noted decrease in PI activity and stimulation of neutrophils in 13 different patients after dialysis. The majority of patients (36\%) were in group D had an abnormal elevated level of serum alpha-1 AT in all the three samples. Similar results were noted by Starzyk et al[9] who showed a significant rise in plasma concentration of alpha-1 AT along with other acute phase proteins in 24 patients before and after dialysis, which they attributed to haemoconcentration.

NBT Test-Dialysis generally appears to induce neutrophil activation. Groupwise, the levels of NBT positive cell population are almost similar in $\mathrm{A}$ and $\mathrm{C}$ groups, which show an initial high positivity in the predialysis sample. Those of $B$ and D groups are similar in that a normal pre-dialysis NBT positivity is seen, which rises after dialysis. This rise could be due to dialysis membrane, which could have induced an acute phase response. Similar results were noted by Haag et al[10] who found granulocyte activation during haemodialysis, which in the absence of complement activation seemed to be mediated by calcium ions. Horl et al[11] observed granulocyte activation during haemodialysis. They also found that diabetic patients on dialysis released more intragranular enzymes from neutrophils than their non-diabetic haemodialysis patients. Thus, neutrophil abnormalities in diabetics on dialysis may affect the plasma proteinase system and contribute to enhanced plasma protein degradation as well as to enhanced susceptibility to infections. Hypertension was present in most of the patients. ESR was also increased in all patients, which could be due to the disease process itself or due to the anaemia. Blood urea and serum creatinine were raised in almost all the patients with mean values of $120 \mathrm{mg} \%$ and $9 \mathrm{mg} \%$ respectively indicating the uraemic state.

In the light of above findings in many patients, the disease process itself appeared to play a major role in elevating the levels of alpha-1 AT. Only, few patients had revealed reactivity to dialysis (Group B) and continued dialysis in these patients might lead to persistent acute phase reaction and its sequelae of adverse reactions.

\section{CONCLUSION}

The following conclusions were derived from the study: A general phenomenon of acute phase response with raised serum alpha-1 AT and raised NBT positivity is seen in CRF patients. Underlying diseases along with their biochemical and metabolic abnormalities have a role in acute phase reaction. Dialysis procedure also seems to have a role in inducing persistent acute phase reaction in a small population of CRF patients and one has to be watchful for sequelae of adverse reactions thereof in such patients. 


\section{REFERENCES}

1. Charles BC, Lazarus MJ. Dialysis and transplantation in the treatment of renal failure. In: Isselberger KJ, Brauwald E, Wilson JD, eds. Harrison's Principles of Internal Medicine. 13 th ed. Vol. 2. New York: McGraw Hill Inc 1157-9.

2. Albert AD, Rubenstein HM, Hodges LV. Measurement of alpha-1 antitrypsin in serum by immunodiffusion and by enzymatic assay. Clin Chem 1974;20(3):396-9.

3. Barbara B. Haematology: Principles and Procedures. $5^{\text {th }}$ ed. Philadelphia: Lea and Febiger 1988:135-7.

4. Docci D, Bilancioni R, Baldrati L, et al. Serum alpha-1 antitrypsin in haemodialysis patients with dialysis arthropathy. Int J Artif Organs 1993;16(3):123-7.

5. Horl WH, Steinhauer WB, Scollmeyer P. Plasma levels of granulocyte elastase during haemodialysis: effects of different dialyser membranes. Kidney Int 1985;28(5): 791-6.

6. Knudsen F, Neilsen AH, Pederson JO, et al. On the kinetics of complement activation, leucopenia, and granulocyteelastase release induced by haemolysis. Scand J Clin Lab Invest 1985;45(8):759-66.
7. Trznadel K, Luciak M, Paradowski M, et al. Haemodialysis and the acute phase response in chronic uraemic patients. Int J Artif Organs 1989;12(12):762-5.

8. Shcherbakova G, Varakina NI, Iarovaia GA, et al. Status of the kallikrein-kinin system, proteinase inhibitors, and nonspecific resistance factors in patients with chronic kidney failure on haemodialysis as well as kidney transplant recipients. Vopr Med Khim 1991;37(5):40-3.

9. Starzyk J, Bartelik S, Kowlski D. Effect of haemodialysis on the concentration of beta- 2 microglobulin and acute phase proteins in the serum of patients with chronic renal failure. Wiad Lek 1990;43(3-4):114-7.

10. Haag WM, Schollmeyer P, Horl WH. Granulocyte activation during haemodialysis in the absence of complement activation: Inhibition by calcium channel blockers. Eur J Clin Invest 1988;18(4):380-5.

11. Horl WH, Schaefer RM, Schollmeyer P. Enhanced plasma and intracellular levels of main granulocyte components in diabetics on dialysis. Blood Purify 1989;7(6):314-23. 